\title{
MRI of the Breast as Part of the Assessment in Population-Based Mammography Screening
}

\section{MRT der Mamma im Rahmen der Abklärungsdiagnostik im bevölkerungsbezogenen Mammographie-Screening}

Authors

Affiliations
U. Bick $^{1,2}$, F. Engelken ${ }^{1}$, G. Diederichs ${ }^{1}$, R. Dzyuballa ${ }^{2}$, M. Ortmann², E. M. Fallenberg ${ }^{1,2}$

Institut für Radiologie, Charité - Universitätsmedizin Berlin

2 Praxis Dr. Ralph Dzyuballa und Dipl.-Med. Marina Ortmann, Screening-Einheit 2 Berlin

Key words
breast
neoplasms
mammography
screening
MR imaging
assessment

eingereicht 11.1 .2013

akzeptiert 3.4 .2013

\section{Bibliography}

DOI http://dx.doi.org/ 10.1055/s-0033-1335518

Published online: 05.06 .2013

Fortschr Röntgenstr 2013; 185: 849-856 @ Georg Thieme Verlag KG Stuttgart · New York . ISSN 1438-9029

\section{Correspondence}

Prof. Ulrich Bick

Institut für Radiologie, Charité Campus Mitte

Schumannstraße 20/21

10115 Berlin

Germany

Tel.: ++ 49/30/450527001

Fax: ++49/30/450527968

Ulrich.Bick@charite.de

\section{Zusammenfassung}

$\nabla$

Ziel: Evaluierung der Indikationen und Bedeutung der MRT der Brust als Abklärungsmodalität im bevölkerungsbezogenen Mammographie-Screening. Material und Methoden: 135 konsekutive, zwischen April 2007 und Oktober 2012 als Teil der Abklärungsdiagnostik in einer MammographieScreening-Einheit vor Festlegung einer definitiven Handlungsempfehlung (z. B. sicher benigne oder maligne) durchgeführte kontrastverstärkte MRT Untersuchungen der Brust wurden retrospektiv ausgewertet. Insgesamt handelt es sich bei den Abklärungsuntersuchungen mit MRT um weniger als $2 \%$ aller Abklärungsuntersuchungen in dieser Screening-Einheit. Alle MRT-Untersuchungen wurde im Rahmen der klinischen Routine an einem 1,5T oder 3 T MRT-Ganzkörpertomographen mit einem Standard Protokoll für eine dynamische kontrastverstärkte MRT der Brust untersucht.

Ergebnisse: Bei den 135 Studienpatientinnen wurden insgesamt 30 Malignome bei 28 Patientinnen gefunden, einschließlich zwei bilateraler Karzinome. Bei einer Patientin wurde ein Non-Hodgkin-Lymphom diagnostiziert, von den übrigen 29 malignen Läsionen waren 3 (10\%) In-situ Karzinome (DCIS) und 26 (90\%) invasive Karzinome einschließlich drei multifokaler bzw. multizentrischer Karzinome. Bei allen 26 detektierten invasiven Karzinomen waren die Lymphknoten negativ und bei 25/29 (86\%) der detektierten Mammakarzinome handelte es sich um frühe Tumorstadien (Stadium 0 oder I). 53 der 135 MRT Untersuchungen $(39,3 \%)$ wurden als malignomverdächtig (BIRADS 4 oder 5) eingestuft. Keines der Karzinome wurde im MRT übersehen. Sensitivität, Spezifität, positiver prädiktiver Wert und negativer prädiktiver Wert der MRT bezogen auf Patienten waren $100 \%, 77 \%, 0,53$, und 1 .

Schlussfolgerung: Die MRT ist hilfreich bei der Problemlösung in der Abklärungssituation im Mam-

\section{Abstract \\ $\nabla$}

Purpose: To evaluate the indications and impact of MRI of the breast as an assessment modality in population-based mammography screening.

Materials and Methods: 135 consecutive contrastenhanced MRI exams of the breast, which were performed between April 2007 and October 2012 as part of the assessment at one mammography screening unit before issuance of a final management recommendation (e.g. definitely benign or malignant), were retrospectively reviewed. Overall, the cases with an MRI exam of the breast during assessment represent less than $2 \%$ of all assessment cases at this screening unit. All MRI exams were performed as part of the routine clinical care on a $1.5 \mathrm{~T}$ or $3 \mathrm{~T}$ whole-body magnet using a standard dynamic breast MRI protocol.

Results: In the 135 study patients, a total of 30 malignancies in 28 patients were found, including two bilateral cancers. One patient was diagnosed with a non-Hodgkin lymphoma, and of the remaining 29 malignant lesions, 3 (10\%) were in-situ cancers (DCIS) and 26 (90\%) were invasive breast cancers including 3 multifocal or multicentric cancers. All 26 detected invasive cancers were lymph-node negative and 25/29 (86\%) of the detected breast cancer were early stage cancers (stage 0 or 1 ). 53 of the 135 MRI exams (39.3\%) were suspicious for malignancy (BIRADS 4 or 5) with no cancer missed by MRI. The sensitivity, specificity, positive predictive value, and negative predictive value of the MRI on a per patient basis were $100 \%, 77 \%, 0.53$, and 1 , respectively.

Conclusion: MRI is a useful problem-solving tool in mammography screening assessment with a high sensitivity and an acceptable positive predictive value.

Citation Format:

- Bick U, Engelken F, Diederichs G etal. MRI of the Breast as Part of the Assessment in Popula- 
mographie-Screening und zeichnet sich in dieser Situation durch eine hohe Sensitivität bei akzeptablem positiven prädiktiven Wert aus.
tion-Based Mammography Screening. Fortschr Röntgenstr 2013; 185: $849-856$

\section{Introduction}

Population-based mammography screening in Germany was gradually introduced across the nation between 2005 and 2009 $[1-4]$. As part of the publicly funded program, all women in Germany aged 50 to 69 years are invited for mammography screening every two years. The program is organized into 94 screening units across Germany, each serving an area of approximately 1000000 inhabitants. The screening units are usually run by one or two responsible physicians ("Programmverantwortlicher Arzt", PVA). All screening mammograms are independently double-read by two certified physicians using a five-step modified BIRADS (Breast Imaging Reporting and Data System, American College of Radiology) scale with level 1 and 2 representing benign readings and $4 \mathrm{a}, 4 \mathrm{~b}$ and 5 representing different levels of suspicion of malignancy. Every case that is scored $4 a, 4 b$ or 5 by at least one of the two radiologists is discussed in a weekly consensus conference, where the final decision whether to recall the woman for assessment is made. With the exception of stereotactic biopsies and breast MRI, which may be referred to outside institutions, the entire assessment chain up to the histological confirmation or exclusion of breast cancer is performed by the PVA in the screening unit. Assessment work-up usually includes a detailed history, clinical exam, comparison with outside prior films, additional mammographic views if necessary as well as bilateral hand-held ultrasound [5]. If a lesion is considered suspicious for malignancy after further work-up, percutaneous biopsy (ultrasound-guided or stereotactic) is performed and the results are discussed in a multidisciplinary conference in the screening unit together with the pathologists and breast surgeons to determine the further management. Traditionally, MRI of the breast has not had a role of any significance during assessment in populationbased mammography screening, simply because by the nature of the program any abnormality detected on a screening mammogram should - if not palpable or visible on ultrasound - be accessible to stereotactic biopsy or open surgical biopsy after wire localization. In the German screening program guidelines [1], MRI of the breast is restricted to patients with a personal history of breast cancer, in whom mammography and ultrasound cannot distinguish between scar tissue and a suspected recurrence. This is the only indication for an MRI of the breast which is also reimbursed by public payers in Germany in the diagnostic setting.

This virtually non-existent role of MRI in the mammography screening assessment situation is in contrast with the fact that MRI of the breast with its unmatched high sensitivity for breast cancer has long been advocated as an excellent problem-solving tool, e. g. for equivocal findings on mammography or ultrasound $[6,7]$. Unfortunately there is very little data in the literature regarding the value of MRI in this setting $[8,9]$. Most studies are small and to our knowledge, there is no study evaluating MRI specifically in the setting of population-based mammography screening. Most authors agree that in the case of a clearly suspicious finding, MRI should not be used as a substitute for percutaneous biopsy [9], which in most situations will provide a definitive answer and at least in the case of ultrasound-guided biopsy will even be significantly cheaper than MRI. The goal of our study was therefore to try to identify certain circumstances in which MRI as part of assessment in mammography screening may provide a benefit.

\section{Materials and Methods}

To identify all consecutive patients who were referred to MRI of the breast during assessment from a single screening unit before issuance of a final management recommendation, the hospital medical records and the documentation in the screening unit were retrospectively reviewed. If one of the following final management recommendations

- definitely benign, return to routine screening

- definitely malignant, referral for treatment

- malignancy cannot be ruled out, open surgical biopsy recommended (e.g. after a percutaneous biopsy resulting in a B3 classification)

was issued before the performance of the MRI, the exam was considered ineligible.

Between April 2007 (start of screening at the screening unit) and October 2012, a total of 139 patients were referred for MRI of the breast as part of the assessment after an abnormal digital screening mammogram. All decisions for referral to MRI were made by one of the two PVAs running the screening unit. The two PVAs of the screening unit both read more than 5000 screening mammograms a year and are personally responsible for all assessment cases in the screening unit (more than 1500 cases per year). Four patients were excluded from analysis: in two patients the MRI exam was performed only after the diagnosis of breast cancer for staging purposes (in both patients MRI confirmed the malignancy with no additional lesions), one patient represented a self-referral in a private patient, who was classified as definitely benign by the screening unit prior to performance of the MRI (MRI was negative and patient was returned to normal screening, two-year follow-up at mammography screening was normal), and one additional patient had to be excluded, since the MRI study had to be aborted after the unenhanced sequences due to preexisting respiratory problems (the non-enhanced scan did not show any suspicious abnormality and the patient was placed on further follow-up, two-year follow-up at mammography screening was normal). The mean age of the remaining 135 study patients at the time of the MRI exam was 57.3 years with a range from 50 - 70 years.

Based on the referral reason, the MRI exams were grouped for further analysis into one of the following four categories:

1. Patients referred to stereotactic biopsy usually for an architectural distortion or subtle density, which could not be reproduced at the stereotactic biopsy system and therefore no biopsy was performed $(n=12)$.

2. Patients after benign percutaneous biopsy with insufficient concordance between initial radiological finding and histopathological biopsy results $(n=20)$. In 10 cases $(50 \%)$ the biopsy was performed under ultrasound guidance and in 10 cases (50\%) a stereotactic biopsy was performed. Biopsy results were classified as B1b in 6 cases, as B2 in 10 cases, and as B3 
in 4 cases. Biopsies classified as B3 were only referred to MRI if no decision could be made in the multidisciplinary conference as to whether to refer the patient to repeat open surgical biopsy or to place the patient on follow-up.

3. A single unifocal finding on mammography and/or ultrasound considered equivocal after full mammographic und sonographic work-up $(n=60)$. In most cases these represented subtle architectural distortions or densities, which were only seen in one view and could not be reproduced in the additional views. In some cases non-specific subtle microcalcifications were present in the area of suspicion, but no cases with unifocal suspicious grouped calcifications were included since these would have been sent straight to stereotactic biopsy.

4. Multiple, usually low-suspicion findings in one or both breasts on mammography and/or ultrasound with no single dominant suspicious lesion accessible to biopsy $(n=43)$.

The 135 study patients represent $81 \%$ of all MRI exams of the breast performed during assessment at the particular screening unit (31 additional patients had their MRI exam at a different outside institution and are therefore not part of this study). With an estimated number of $30-40$ assessment cases per week at the screening unit, the patients with an MRI exam of the breast during assessment represent less than $2 \%$ of all assessment cases at the screening unit. MRI exams were paid for according to the German payment schedule for physicians ("Gebührenordnung für Ärzte", GOÄ) by the screening unit out of the lump sum assessment payment.

All MRI exams were performed as part of the routine clinical care on a $1.5 \mathrm{~T}$ (Magnetom Vision, SymphonyVision or Avanto, Siemens Healthcare, Erlangen, Germany) or $3 \mathrm{~T}$ (Magnetom Skyra, Siemens Healthcare, Erlangen, Germany) whole-body magnet using our standard breast MRI protocol consisting of a paracoronal precontrast T1-weighted spin-echo sequence through the axilla, an axial precontrast T2-weighted fast spin-echo sequence without fat saturation, a coronal or axial dynamic $3 \mathrm{D}$ gradientecho sequence without fat saturation with one precontrast and five series after the administration of a single or double weightadapted dose of Gadolinium contrast material, each series with an acquisition time of approximately one minute, and one late post-contrast T1-weighted spin-echo sequence with fat saturation. The protocol follows the guidelines of the breast imaging working group of the German Radiological Society [10], with the exception that $3 \mathrm{~T}$ systems were included in the study, which were not routinely available at the time of the writing of the guidelines in 2005.

All MRI exams were read in full knowledge of the prior mammographic and sonographic exams by one of three board-certified radiologists, all with more than five years of experience in breast imaging including breast MRI. All three radiologists each read more than 250 breast MRIs per year and all three have experience as readers in the mammography screening program reading more than 5000 mammography exams per year. Two of the three radiologists also routinely perform MRI-guided breast biopsies. Images from the prior exams from the screening unit were digitally imported into the PACS and were available on the workstation during the MRI reading. All other reports and documentation regarding the particular patient were available as printout or through access to the centralized screening database.

A standard BIRADS scale from 0 to 5 was used. BIRADS 6 cases were excluded, since only MRI exams performed prior to the histological confirmation of breast cancer were part of the study. No attempt was made to subdivide BIRADS score 4 into a, b, and c.
For purposes of the sensitivity and specificity analysis, a BIRADS score of 4 or 5 (suspicious for malignancy) on MRI was considered positive, while all other BIRADS scores $(0,1,2,3$, benign or probably benign) were considered negative. Further management of the patients (e.g. biopsy or follow-up) after MRI was determined by the PVA at another assessment visit in the screening unit. For all patients referred to biopsy after MRI, final biopsy and, if applicable, surgical pathology results were available. For patients returned to routine screening or placed on short-term follow-up, all available subsequent screening and diagnostic exams were reviewed for follow-up.

\section{Results}

\section{$\nabla$}

Following the MRI exam, a total of 30 malignancies in 28 patients were found, including two bilateral cancers. One patient was diagnosed with a non-Hodgkin lymphoma. Of the remaining 29 malignant lesions, 3 (10\%) were in-situ cancers (DCIS) and 26 (90\%) were invasive breast cancers including three multifocal or multicentric cancers. 25/29 (86\%) of the detected breast cancer were early stage cancers (stage 0 or 1 ). The characteristics of the detected invasive breast cancers are shown in $\bullet$ Table 1.

All 30 malignant lesions including the two bilateral cancers were correctly identified on MRI. 53 of the 135 MRI exams (39.3\%) were suspicious for malignancy (BIRADS 4 or 5 ) with a positive predictive value of a positive MRI reading calculated per patient of 0.53 ( Table 2,3 ).

In all 53 positive MRI exams, the affected side (in the case of bilateral suspicious findings the side with the higher BIRADS score on MRI) was also positive on the pre-MRI conventional diagnos-

Table 1 Histopathological diagnosis and stage of the 26 detected invasive breast cancers.

Tab. 1 Histopathologische Diagnose und Stadium der 26 detektierten invasiven Karzinome.

\begin{tabular}{|lr|}
\hline histology & \\
\hline invasive ductal cancer & $19(73 \%)$ \\
\hline lobular cancer & $4(15 \%)$ \\
\hline mucinous cancer & $1(4 \%)$ \\
\hline tubular cancer & $1(4 \%)$ \\
\hline apocrine cancer & $1(4 \%)$ \\
\hline grade & $13(50 \%)$ \\
\hline 1 & $11(42 \%)$ \\
\hline 2 & $2(8 \%)$ \\
\hline 3 & $12(46 \%)$ \\
\hline tumor size & $16(62 \%)$ \\
\hline$\leq 10$ mm & \\
\hline$<15$ mm & $3(12 \%)$ \\
\hline tumor stage & $9(35 \%)$ \\
\hline pT1a & $10(38 \%)$ \\
\hline pT1b & $3(12 \%)$ \\
\hline pT1 ${ }^{1}$ & $1(4 \%)$ \\
\hline pT2 & $26(100 \%)$ \\
\hline pT3 & $0(0 \%)$ \\
\hline lymph nodes & \\
\hline negative & \\
\hline positive & \\
\hline \begin{tabular}{l} 
Including one pT1b(m) and two pT1c(m) cancers. \\
\hline In $25 / 26$ patients a sentinel node biopsy and in one patient a full axillary node sam-
\end{tabular} \\
\hline pling was performed. & \\
\hline
\end{tabular}


tic work-up. All patients with a positive MRI exam had at least one biopsy of the affected breast. In 19 of 53 patients (35.8\%), two or more biopsies of the affected breast were necessary for final histological confirmation. Since all positive MRI cases on the affected side had a correlate on mammography and/or ultrasound, no MRI-guided biopsy had to be performed.

In 5 of the 53 positive MRI exams, the MRI showed a second suspicious lesion in the contralateral breast. Three contralateral MRI findings had a correlate on mammography and/or ultrasound performed in the screening unit prior to MRI. Two of these turned out to be malignant (bilateral concurrent breast cancer) and in the third case ultrasound-guided biopsy showed benign fibrocystic change, which was felt not to be sufficiently concordant and repeat open excisional biopsy was performed demonstrating a benign papilloma. No ultrasound or mammographic correlate for the two other contralateral low-suspicion MRI lesions was found on a second-look assessment visit and the patients were placed on further follow-up.

Of the three multifocal or multicentric cancers, one bicentric cancer with two separate lesions in different quadrants already sus-

Table 2 Relationship between MRI BIRADS score and final diagnosis. Analysis per patient. In the case of multiple or bilateral findings, the highest BIRADS score was used.

Tab. 2 Beziehung zwischen MRT BIRADS Einstufung und endgültiger Diagnose. Analyse bezogen auf Patienten. In Fällen mit multiplen oder bilateralen Befunden wurde die höchste BIRADS Einstufung verwendet.

\begin{tabular}{|lcc|}
$\begin{array}{l}\text { MRI BIRADS } \\
\text { score }\end{array}$ & $\begin{array}{l}\text { frequency of BIRADS } \\
\text { ratings }^{1}\end{array}$ & $\begin{array}{l}\text { fraction with malignant } \\
\text { outcome }\end{array}$ \\
\hline MRI negative & $82(60.7 \%)$ & $0(0 \%)$ \\
\hline BIRADS 0 & $4(3.0 \%)$ & $0(0 \%)$ \\
\hline BIRADS 2 & $61(45.2 \%)$ & $0(0 \%)$ \\
\hline BIRADS 3 & $17(12.6 \%)$ & $0(0 \%)$ \\
\hline MRI positive & $53(39.3 \%)$ & $28(52.8 \%)$ \\
\hline BIRADS 4 & $34(25.2 \%)$ & $17(50.0 \%)$ \\
\hline BIRADS 5 & $19(14.1 \%)$ & $11(57.9 \%)$ \\
\hline total & $135(100 \%)$ & $28(20.7 \%)$ \\
\hline
\end{tabular}

1 Percentages represent frequency of BIRADS score relative to all exams.

2 Percentages represent fraction of cases with malignant outcome (in-situ and invasive combined) for the specific BIRADS score.

${ }^{3}$ No cases were rated as BIRADS 1 on MRI. pected on the initial screening mammogram also had two separate suspicious lesions on MRI, both of which were confirmed as malignant (invasive) through percutaneous biopsy prior to surgery. The other two cancers were multifocal (one trifocal invasive lobular cancer with one separate focus of DCIS and one bifocal invasive ductal cancer with two additional areas of $\mathrm{ADH}$ ). In both cases multifocality was predicted by both conventional imaging and MRI, but no attempt was made to confirm the multifocality preoperatively by percutaneous biopsy. One other patient with a bilateral cancer had a second suspicious lesion in a separate quadrant in one of the breasts, which was suspicious both on conventional imaging and MRI. Ultrasound-guided biopsy resulted in the diagnosis of a benign papilloma, which was confirmed by subsequent excisional biopsy.

Eight stereotactic biopsies in seven patients (one bilateral biopsy) were performed after MRI for microcalcifications or architectural distortions in breasts which did not show a suspicious finding on MRI ( $\bullet$ Fig. 1). None of these biopsies led to the diagnosis of a malignancy. In three cases a repeat open surgical biopsy was performed for a B3 lesion (one atypical ductal hyperplasia, one flat epithelial atypia, one radial scar), which did not show any evidence of malignancy. In the remaining five stereotactic biopsies, histology showed a benign fibrocystic change and sclerosing adenosis.

In total, 20 lesions with uncertain malignant potential (classified as B3) were found after percutaneous biopsy ( $\bullet$ Table 4 ). This represents $30 \%(20 / 66)$ of all lesions in which a percutaneous biopsy was performed. Of the 16 lesions that were positive on MRI, a malignancy was found on repeat biopsy in 6 (38\%) (2 DCIS, 4 invasive cancers). Of the remaining 4 lesions that were negative on MRI, none turned out to be malignant.

Of the 81 patients with a benign or probably benign assessment on MRI, 29 (36\%) had histological confirmation and/or follow-up of more than two years. A malignancy was not found in any of these 29 patients during follow-up.

\section{Discussion}

$\nabla$

In mammography screening, the overwhelming majority of patients recalled for abnormal findings on a screening mammogram can sufficiently be worked-up by using additional mammo-

Table 3 Diagnostic accuracy of MRI reading in relationship to the indication for the exam. Analysis per patient. In the case of multiple or bilateral findings, the highest BIRADS score was used. $n p v=$ negative predictive value. $p p v=$ positive predictive value.

Tab. 3 Diagnostische Genauigkeit der MRT-Befunde in Beziehung auf die Indikation zur Untersuchung. Analyse bezogen auf Patienten. In Fällen mit multiplen oder bilateralen Befunden wurde die höchste BIRADS Einstufung verwendet.

\begin{tabular}{|c|c|c|c|c|c|c|c|}
\hline indication for the MRI exam & $\mathbf{n}^{1}$ & positive MRI² & malignant $^{3}$ & sensitivity & specificity & ppv & npv \\
\hline $\begin{array}{l}\text { lesion could not be sufficiently } \\
\text { localized during biopsy attempt }\end{array}$ & $12(8.9 \%)$ & $2(16.7 \%)$ & $1(8.3 \%)$ & $100 \%$ & $91 \%$ & 0.50 & 1 \\
\hline $\begin{array}{l}\text { benign biopsy with insufficient } \\
\text { radiological-pathological } \\
\text { concordance }\end{array}$ & $20(14.8 \%)$ & $6(35.0 \%)$ & $4(20.0 \%)$ & $100 \%$ & $88 \%$ & 0.67 & 1 \\
\hline $\begin{array}{l}\text { equivocal finding or minimal sign } \\
\text { (single finding) }\end{array}$ & $60(44.4 \%)$ & $22(36.7 \%)$ & $13(21.7 \%)$ & $100 \%$ & $81 \%$ & 0.59 & 1 \\
\hline $\begin{array}{l}\text { equivocal finding or minimal sign } \\
\text { (multiple findings) }\end{array}$ & $43(31.9 \%)$ & $23(53.5 \%)$ & $10(23.3 \%)$ & $100 \%$ & $61 \%$ & 0.43 & 1 \\
\hline total & $135(100 \%)$ & $53(39.3 \%)$ & $28(20.7 \%)$ & $100 \%$ & $77 \%$ & 0.53 & 1 \\
\hline
\end{tabular}

1 Percentages represent frequency of type of indication relative to all exams.

2 Percentages represent fraction of cases with positive MRI relative to the total number of cases with this specific indication.

3 Percentages represent fraction of cases with malignant outcome (in-situ and invasive combined) relative to the total number of cases with this specific indication. 
Table 4 Final outcome of lesions with uncertain malignant potential (classified as B3) on percutaneous biopsy. In 8 cases the B3 classification was made after an ultrasound-guided biopsy, in 13 cases after a stereotactic biopsy including one patient, who had first an ultrasound-guided and then a stereotactic biopsy of the same lesion with both biopsies resulting in a B3 classification (radial scar). All lesions classified as B3 had final histopathological confirmation through surgical excision.

Tab. 4 Endgültige Histologie bei Läsionen mit unsicherem malignen Potential (klassifiziert als B3) in der perkutanen Biopsie. In 8 Fällen wurde die B3-Läsion bei einer Ultraschall-gesteuerten Biopsie gefunden, in 13 Fällen bei einer stereotaktischen Biopsie, einschließlich einer Patientin, die zunächst eine ultraschallgesteuerte Biopsie und dann eine stereotaktische Biopsie der gleichen Läsion hatte, beide Biopsien mit Nachweis einer B3-Läsion (radiäre Narbe). Bei allen B3-Läsionen lag ein endgültiges histopathologisches Ergebnis nach operativer Exzision der Läsion vor.

\begin{tabular}{|c|c|c|c|c|c|}
\hline \multirow{2}{*}{$\begin{array}{l}\text { pathohistological finding } \\
\text { on percutaneous biopsy }\end{array}$} & \multirow[t]{2}{*}{ number of lesions } & \multicolumn{4}{|c|}{ final histopathological diagnosis } \\
\hline & & benign & in-situ & invasive & all malignant \\
\hline atypical ductal hyperplasia & 5 & 2 & 2 & 1 & $3(60 \%)$ \\
\hline MRI positive & 4 & 1 & 2 & 1 & $3(75 \%)$ \\
\hline MRI negative & 1 & 1 & 0 & 0 & $0(0 \%)$ \\
\hline flat epithelial atypia ${ }^{1}$ & 4 & 2 & 0 & 2 & $2(50 \%)$ \\
\hline MRI positive ${ }^{1}$ & 3 & 1 & 0 & 2 & $2(67 \%)$ \\
\hline MRI negative & 1 & 1 & 0 & 0 & $0(0 \%)$ \\
\hline lobular neoplasia ${ }^{2}$ & 2 & 1 & 0 & 1 & $(50 \%)$ \\
\hline papilloma² & 4 & 4 & 0 & 0 & $0(0 \%)$ \\
\hline radial scar & 5 & 5 & 0 & 0 & $0(0 \%)$ \\
\hline MRI positive & 3 & 3 & 0 & 0 & $0(0 \%)$ \\
\hline MRI negative & 2 & 2 & 0 & 0 & $0(0 \%)$ \\
\hline all B3 lesions & 20 & 14 & 2 & 4 & $6(30 \%)$ \\
\hline MRI positive & 16 & 10 & 2 & 4 & $6(38 \%)$ \\
\hline MRI negative & 4 & 4 & 0 & 0 & $0(0 \%)$ \\
\hline
\end{tabular}

Flat epithelial atypia $(\mathrm{FEA})=$ columnar cell change with atypia.

Radial scar = complex sclerosing lesion.

${ }^{1}$ Including two cases, in which lobular neoplasia was found at percutaneous biopsy in addition to the flat epithelial atypia.

${ }^{2}$ All lesions in this category were positive on MRI. No separation was attempted between lobular neoplasia grade I (atypical lobular hyperplasia) and lobular neoplasia grade II (lobular carcinoma in situ, LCIS).

graphic views and/or ultrasound followed, if necessary, by percutaneous biopsy. This is consistent with our finding that less than two percent of all patients recalled to assessment were referred for MRI of the breast. Errors during assessment in mammography screening leading to a delayed diagnosis of breast cancer are rare but do occur [11-14] and thus there is potential to reduce those errors by including MRI of the breast during the assessment in selected patients. The strength of MRI is its unmatched high sensitivity and negative predictive value [7], which is especially evidenced by the now extensively available experience with MRI screening in high-risk women [15 - 17]. If MRI is able to reliably exclude malignancy in a portion of patients with equivocal findings during assessment, these patients can safely be returned to routine screening and further short-term follow-up exams or invasive procedures such as repeat percutaneous or open surgical biopsies, both of which represent a significant burden to the patients, can be avoided. In our study, almost $60 \%$ of the patients had no evidence of malignancy on MRI and the majority of these could be returned to routine screening. A malignancy was not found in any of the patients with a negative MRI in our series at biopsy performed despite the negative MRI or during follow-up. To be useful in this setting, MRI has to achieve a negative predictive value of close to $100 \%[8,18]$. Since the sensitivity for DCIS is lower than for invasive cancers, MRI should not be used to exclude malignancy in cases with suspicious microcalcifications $[19,20]$. These cases should instead go straight to stereotactic biopsy. In our series, no cases with suspicious microcalcifications as the dominant finding were included, although some cases did have low-suspicion microcalcifications either distant from or at the site of another suspicious mammographic abnormality. The negative predictive value of MRI will also be influenced by the underlying probability of malignancy. Assuming a constant sensi- tivity of MRI, the negative predictive value of MRI will be higher if the underlying probability of malignancy is low. Cases with a highly suspicious finding on mammography and/or ultrasound therefore do not represent a good indication for MRI and these cases should go straight to (if necessary repeat) biopsy [18]. The value of MRI during assessment will be highest for subtle lowsuspicion findings or "minimal signs", in which the negative predictive value of MRI will be high and MRI will pick up a small number of cancers with a reasonable positive predictive value, which otherwise could have been missed.

In our study, MRI was able to predict malignancy with an acceptable positive predictive value of slightly more than $50 \%$, which fulfills the German Screening Guidelines requiring a malignantto-benign ratio for percutaneous biopsies of at least $1: 1$ [1]. This is also similar to the positive predictive value of biopsy recommendations in mammography screening after the regular assessment based on mammography and ultrasound [3]. This high malignancy yield for MRI in our study is even more remarkable when considering that predominantly low-suspicion findings and "minimal signs" [21] were referred to MRI.

No studies using MRI as a problem-solving tool in the setting of a population-based mammography screening program are available for comparison. The study with a setup most closely resembling ours is a study by Moy et al., who studied MRI as a problem solving tool in 115 patients with equivocal findings on mammography, which remained inconclusive after further mammographic and sonographic workup [22]. In their study the sensitivity, specificity, positive predictive value and negative predictive value were $100 \%, 91.7 \%, 0.40$ and 1.00 , respectively, which is very similar to the results in our study ( $\bullet$ Table 2 ). The sensitivity of MRI in our study (100\%) was higher than the reported sensitivity of $84-94 \%$ for the combination of MRI and mammography 

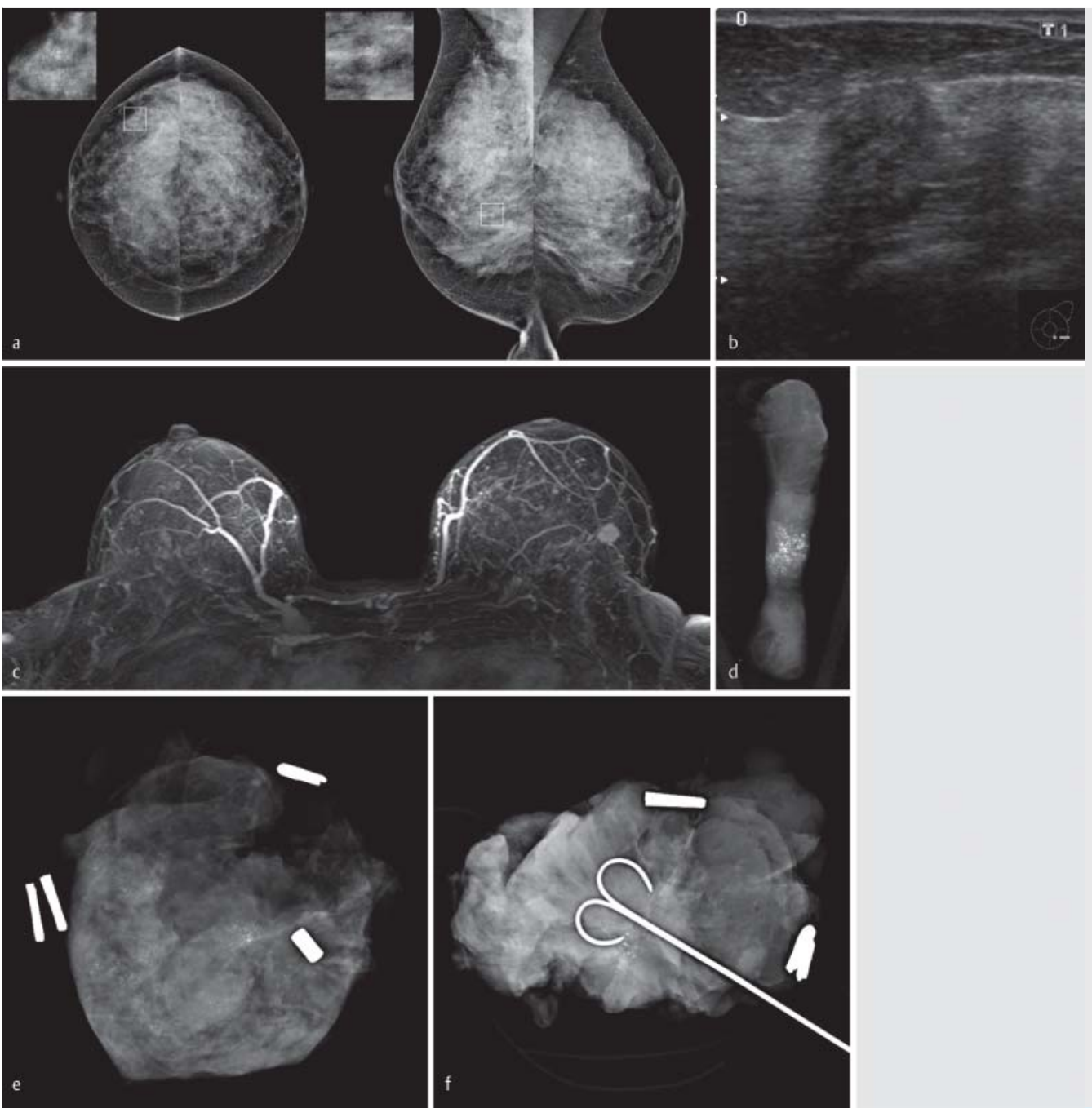

Fig. 1 50-year-old female invited for first round of mammography screening. Bilateral two-view screening mammograms a with subtle area of microcalcifications in the outer part of the right breast detected only by one of the two readers. In the consensus conference, it was decided to recall the patient for further workup. Additional mammographic imaging including magnification views confirmed the calcifications in the right breast, which were not present on prior outside films. In addition, bilateral hand-held ultrasound performed during the assessment visit showed a small, poorly defined hypoechoic lesion in the left breast $\mathbf{b}$, which did not have a mammographic correlate. The patient was referred to MRI, which demonstrated a highly suspicious enhancing lesion (rated BIRADS 5) in the left breast corresponding in location to the lesion found on ultrasound. The lesion is well seen on the axial MIP projection of the subtraction images in the second minute after contrast administration c. No suspicious enhancement was found in the right breast. An ultrasound-guided biopsy of the lesion in the left breast was performed showing fibrocystic change without evidence of malignancy, the outcome being rated as not concordant (B1b). The stereotactic vacuum-assisted biopsy of the calcifications in the right breast $\mathbf{d}$ performed despite the normal MRI of the right breast showed flat epithelial atypia rated as B3. In the multidisciplinary conference at the screening unit bilateral excisional biopsies were recommended. The right specimen radiograph e shows the marker clip from the stereotactic biopsy with extensive surrounding residual calcifications. The left specimen radiograph $\mathbf{f}$ with the localization wire in place demonstrates a small suspicious spiculated mass, which was not visible on the full mammogram, not even in retrospect. Histopathology revealed a 11-mm tubular cancer [pT1c pNO(sn) G1] in the left breast, no malignancy was found in the right breast.

Abb. 1 a 50-jährige Erstteilnehmerin am Mammographie-Screening. Auf der beidseitigen Screening-Mammographie in zwei Ebenen a erkennt man rechts außen eine sehr diskrete Mikrokalkgruppe, die nur von einem der beiden Befunder als verdächtig eingestuft wurde. In der Konsensuskonferenz wurde beschlossen, die Patientin zur Abklärung einzuladen. Mammographische Zusatzaufnahmen einschließlich gezielter Vergrößerungsaufnahmen bestätigten Mikroverkalkungen in der rechten Brust, die auf auswärtigen Voraufnahmen nicht erkennbar waren. Ein zusätzlich im Rahmen der Abklärung durchgeführter beidseitiger Ultraschall zeigte eine kleine, relativ schlecht definierte echoarme Läsion in der linken Brust b ohne mammographisches Korrelat. Die Patientin wurde zur MRT überwiesen, die eine hochsuspekte anreichernde Läsion (eingestuft als BIRADS 5) in der linken Brust, korrespondierend zu der Läsion im Ultraschall, zeigte. Die Läsion ist gut zu erkennen auf der axialen MIP-Projektion der Subtraktionsaufnahmen in der zweiten Minute nach Kontrastmittelapplikation c. Keine suspekte Anreicherung war in der rechten Brust zu erkennen. Eine ultraschall-gestützte Stanzbiopsie der Läsion in der linken Brust ergab Veränderungen im Sinne einer fibrozystischen Mastopathie ohne Hinweis auf Malignität, der Befund wurde als nicht ausreichend konkordant eingestuft (B1b). Die stereotaktische Vakuumbiopsie der Mikroverkalkungen in der rechten Brust $\mathbf{d}$, die trotz der unauffälligen MRT der rechten Brust durchgeführt wurde, ergab eine flache epitheliale Atypie, die als B3 eingestuft wurde. In der multidisziplinären Konferenz in der Screening-Einheit wurde die Durchführung einer beidseitigen offen Exzisionsbiopsie empfohlen. Die Präparateradiographie rechts e zeigt den Markierungsclip von der Vakuumbiopsie mit ausgedehnten umgebenden Mikroverkalkungen. In der Präparateradiographie links $\mathbf{f}$ mit Markierungsdraht in situ erkennt man eine suspekte sternförmige Verdichtungsfigur, die auch retrospektiv nicht in der Übersichtsaufnahme erkennbar war. Die histopathologische Aufarbeitung ergab ein $11 \mathrm{~mm}$ großes tubuläres Karzinom [pT1c pNO(sn) G1] in der linken Brust, in der rechten Brust wurden keine malignen Veränderungen gefunden. 
in the high-risk screening setting [17]. Two factors may have contributed to this. Many cases of DCIS associated with microcalcifications did not enter our study, because these would have been referred straight to stereotactic biopsy, preventing false-negative MRIs in some of these cases. The other important aspect is that in our study the MRI was read in full knowledge of the prior screening mammogram and diagnostic work-up, thus improving the sensitivity of MRI. In most high-risk screening studies, care was taken to read mammography and MRI independently for study purposes. The positive predictive value of an MRI-based biopsy recommendation in our study (0.53) fell within the published range of positive predictive values for other MRI indications such as high-risk screening [15] or breast cancer staging [23]. A surprisingly high rate of lesions with uncertain malignant potential (classified as B3 after percutaneous biopsy) was found in our study ( $\odot$ Table 4 ). Approximately $30 \%$ of all lesions that underwent percutaneous biopsy represented high-risk lesions classified as B3. This is higher than the reported rate of $15 \%$ for B3 lesions in digital mammography screening overall [24]. This is likely related to the fact that this series consisted of a highly selected group of subtle findings, with the clearly suspicious findings going straight to biopsy without the need for MRI. In addition, many of the lesions with uncertain malignant potential included in this study will show suspicious enhancement on MRI virtually indistinguishable from malignant changes [25]. That this group of B3 lesions is highly relevant for the detection of early stage cancers (both in-situ and invasive) in mammography screening is indicated by the fact that the positive predictive value for malignancy in this group was $30 \%$, similar to the positive predictive value of $28 \%$ in the series of Weigel et al. [24]. The upgrade rate to malignancy was lower for papillomas and radial scars in our study (no cancers found in both entities), which is similar to the data reported in the literature [24]. Linda et al. have concluded from their study that patients with papillomas or radial scars on percutaneous biopsy may not need to undergo surgical excision if MRI is negative [26]. When using MRI to predict whether surgical excision is necessary in patients with highrisk lesions classified as B3 on percutaneous biopsy, it is important to realize that MRI will probably have a higher accuracy if performed prior to biopsy as in our study rather than after percutaneous biopsy, since changes related to biopsy, which might impair the diagnostic accuracy of MRI, can be avoided by performing MRI prior to biopsy.

The study has several limitations. The study group represents only slightly more than $80 \%$ of all MRI exams performed during assessment at the screening unit during the study period, since in a small number of patients the MRI exams were performed at a different outside institution. However, since selection of the exam site was based on patient preference (e.g. proximity of the site to the patient's home) and not on medical reasons, this fact should not have influenced the results.

Due to the retrospective nature of the study, MRI exams were performed on different MRI systems with consecutive differences in protocol over a more than five-year time frame and were read by three different radiologists. However, we believe that this makes the results more representative of the routine clinical practice. The ability to maintain such a high sensitivity and negative predictive value with MRI in this setting throughout the entire study period is very encouraging and speaks of the robustness of this technique.

Histological confirmation or reliable follow-up data for the cases with a benign or probably benign assessment on MRI was only available in $36 \%$ (29/81) of the patients, which is mainly due to the retrospective nature of the study (no patient consent was available to contact the patients directly for follow-up). In addition, considering the two-year screening interval, we would have had to allow for a follow-up period after the last MRI exam of at least two years, which would have reduced our study period by more than one-third. However, cancer was not found in any of the 29 patients with a benign or probably benign assessment on MRI, in whom histological confirmation or follow-up was available.

While two of the indications for MRI in our study (biopsy with benign but not concordant results and attempted but aborted biopsy) are relatively clearly defined, the most common indication (single or multiple equivocal findings) is subjective and difficult to operationalize as part of a general management recommendation. However, it is clear from prior work [9] that MRI should not be used to replace percutaneous biopsy and findings easily accessible to percutaneous biopsy do not represent an indication for MRI. Accordingly, special care was taken in our study not to include such patients.

\section{Conclusion \\ $\nabla$}

MRI can predict or exclude the presence of malignancy with high accuracy in patients with inconclusive results after standard assessment in mammography screening, although the absolute number of assessment cases in which MRI is indicated is small compared to the overall number of patients recalled to assessment.

\section{Acknowledgement}

$\nabla$

This manuscript is dedicated to Professor Bernd Hamm for his 60th birthday.

\section{References}

1 Kassenärztliche Bundesvereinigung. Einführung eines bundesweiten Mammographie-Screening-Programms. Dtsch Arztebl Int 2004; 101 Beilage Heft 4

2 Bick $U$. Mammographie-Screening in Deutschland: Wie, wann und warum? Fortschr Röntgenstr 2006; 178: 957-969

3 Malek D, Rabe P. Evaluationsbericht 2008 - 2009. Ergebnisse des Mammographie-Screening-Programms in Deutschland. Berlin: Kooperationsgemeinschaft Mammographie; 2012

4 Biesheuvel C, Weigel S, Heindel W. Mammography Screening: Evidence, History and Current Practice in Germany and Other European Countries. Breast Care (Basel) 2011; 6: 104-109

5 Weigel S, Biesheuvel C, Berkemeyer S et al. Digital mammography screening: how many breast cancers are additionally detected by bilateral ultrasound examination during assessment? Eur Radiol 2013; 23: 684-691

6 Müller-Schimpfle MP, Heindel W, Kettritz U et al. Konsensustreffen der Kursleiter in der Mammadiagnostik am 7.5.2011 in Frankfurt am Main - Magnet-Resonanz-Tomografie der Mamma. Fortschr Röntgenstr 2012; 184: 919-924

7 Mann RM, Kuhl CK, Kinkel K et al. Breast MRI: guidelines from the European Society of Breast Imaging. Eur Radiol 2008; 18: 1307-1318

8 Kuhl CK. Current status of breast MR imaging. Part 2. Clinical applications. Radiology 2007; 244: 672-691

9 Yau EJ, Gutierrez RL, DeMartini WB et al. The utility of breast MRI as a problem-solving tool. Breast J 2011; 17: 273-280

10 Arbeitsgemeinschaft Mammadiagnostik der Deutschen Röntgengesellschaft. Empfehlungen zur MR-Mammographie. Fortschr Röntgenstr 2005; 177 : $474-475$ 
11 Rakha EA, Lee AH, Reed J et al. Screen-detected malignant breast lesions diagnosed following benign (B2) or normal (B1) needle core biopsy diagnoses. Eur J Canc 2010; 46: 1835 - 1840

12 Bennett ML, Welman CJ, Celliers LM. How reassuring is a normal breast ultrasound in assessment of a screen-detected mammographic abnormality? A review of interval cancers after assessment that included ultrasound evaluation. Clin Radiol 2011; 66: 928 -939

13 Ciatto S, Houssami N, Ambrogetti D et al. Minority report - false negative breast assessment in women recalled for suspicious screening mammography: imaging and pathological features, and associated delay in diagnosis. Breast Cancer Res Treat 2007; 105: $37-43$

14 Warren R, Allgood P, Hunnam $G$ et al. An audit of assessment procedures in women who develop breast cancer after a negative result. J Med Screen 2004; 11: 180 - 186

15 Lehman $C D$, Blume JD, Weatherall $P$ et al. Screening women at high risk for breast cancer with mammography and magnetic resonance imaging. Cancer 2005; 103: $1898-1905$

16 Passaperuma K, Warner E, Causer PA et al. Long-term results of screening with magnetic resonance imaging in women with BRCA mutations. Br J Cancer 2012; 107: 24-30

17 Warner E, Messersmith $H$, Causer $P$ et al. Systematic review: using magnetic resonance imaging to screen women at high risk for breast cancer. Ann Intern Med 2008; 148: 671 - 679

18 Bluemke DA, Gatsonis CA, Chen MH et al. Magnetic resonance imaging of the breast prior to biopsy. JAMA 2004; 292: 2735-2742
19 Uematsu T, Yuen S, Kasami M et al. Dynamic contrast-enhanced MR imaging in screening detected microcalcification lesions of the breast: is there any value? Breast Cancer Res Treat 2007; 103: 269-281

20 Cilotti A, Iacconi C, Marini C et al. Contrast-enhanced MR imaging in patients with BI-RADS 3-5 microcalcifications. Radiol med 2007; 112: $272-286$

21 Maes RM, Dronkers DJ, Hendriks JH et al. Do non-specific minimal signs in a biennial mammographic breast cancer screening programme need further diagnostic assessment? Br J Radiol 1997; 70: 34-38

22 Moy L, Elias K, Patel $V$ et al. Is breast MRI helpful in the evaluation of inconclusive mammographic findings? Am J Roentgenol 2009; 193: 986-993

23 Houssami N, Ciatto S, Macaskill P et al. Accuracy and surgical impact of magnetic resonance imaging in breast cancer staging: systematic review and meta-analysis in detection of multifocal and multicentric cancer. J Clin Oncol 2008; 26: 3248-3258

24 Weigel S, Decker T, Korsching E et al. Minimal Invasive Biopsy Results of "Uncertain Malignant Potential" in Digital Mammography Screening: High Prevalence but also High Predictive Value for Malignancy. Fortschr Röntgenstr 2011; 183: $743-748$

25 Heller SL, Moy L. Imaging features and management of high-risk lesions on contrast-enhanced dynamic breast MRI. Am J Roentgenol 2012; 198: $249-255$

26 Linda A, Zuiani C, Furlan A et al. Nonsurgical management of high-risk lesions diagnosed at core needle biopsy: can malignancy be ruled out safely with breast MRI? Am J Roentgenol 2012; 198: 272 - 280 